\title{
PERCEPÇÃO DAS MULHERES IMIGRANTES HAITIANAS SOBRE CONCEPÇÃO DE CORPO, SAÚDE E CUIDADO
}

\author{
Marli Aparecida Rocha de Souza ${ }^{1}$, Aline Dalpra Rosa ${ }^{2}$, Aida Maris Peres ${ }^{3}$, Flaviane da \\ Silva $^{4}$, Ingrid Margareth Voth Lowen ${ }^{5}$, Silvana Regina Rossi Kissula Souza ${ }^{6}$ \\ 1,3,4,5 e 6 Universidade Federal do Paraná, Brasil. ${ }^{1}$ marlirochasouza2@gmail.com; ${ }^{3}$ aidamaris.peres@gmail.com \\ ${ }^{4}$ fla.andreele@gmail.com, ${ }^{5}$ pilowen@gmail.com, ${ }^{6}$ skissula@ufpr.br \\ ${ }^{2}$ Centro Universitário Dom Bosco; Universidade Federal do Paraná, Brasil. aline.dalpra.rosa@hotmail.com
}

\begin{abstract}
Resumo. O acolhimento das mulheres imigrantes haitianas nos serviços de saúde brasileiros depende do conhecimento sobre como elas percebem o corpo, a saúde e o que pensam sobre o cuidado. Objetivo: identificar a percepção das mulheres haitianas quanto ao corpo, cuidado e saúde. Método: Pesquisa descritiva de abordagem qualitativa, realizada de janeiro a julho de 2017 em município do Sul do Brasil, com participação de 10 mulheres. Utilizou-se Foucault como referencial na análise dos discursos. Resultados: A faixa etária prevaleceu entre 24 e 45 anos, oito mulheres tinham filhos e cinco, os filhos nasceram no Brasil. Durante as entrevistas as mulheres estavam com vestimentas coloridas características da cultura negra e a enalteciam, fazendo tranças no cabelo entre si. Ao serem questionadas sobre corpo apontavam nele o que gostavam; sobre saúde informaram ser hospital; e, sobre cuidado, relataram ser estabelecido na relação do cuidar de si e do outro para estarem bem. Conclusões: Embora estas mulheres, demonstrassem um empoderamento sobre si, seu corpo e sua cultura, viam o cuidado como prática feminina e a ótica foucaultiana ajudou na construção da harmonização da teoria com a realidade.
\end{abstract}

Palavras Chave: Imigrantes; Grupo de Ascendência Continental Africana; Gênero; Enfermagem em Saúde Comunitária; Saúde da População.

\section{PERCEPTION OF HAITIAN IMMIGRANT WOMEN ON BODY CONCEPTION, HEALTH AND CARE}

Abstract. The reception of Haitian immigrant women in Brazilian health services depends on knowledge about how they perceive the body, health and what they think about care. Objective: to identify the perception of Haitian women in terms of body, care and health. Method: Descriptive and qualitative research, from January to July 2017 in one southern city of Brazil, with the participation of 10 women. Foucault was used to perform the discourse analysis. Results: The age group prevailed between 24 and 45 years, eight women had children and five, the children were born in Brazil. During the interviews, the women wore colorful clothing characteristic of black culture and praised it, braiding their hair among themselves. When asked about the body, they pointed out what they liked about their own body, when asked about health they reported a link to the hospital. Regarding care, they reported that is established when they are able of taking care of themselves and the others to be well. Conclusions: Although these women demonstrated empowerment about themselves, their body and their black culture, they saw care as a feminine practice and Foucault's optics helped to build the harmonization of theory with reality.

Keywords: Immigrants; African Continental Ancestry Group; Genre; Community Health Nursing; Population Health. 


\section{INTRODUÇÃO}

O Haiti foi a primeira república negra a declarar independência no mundo, no ano de 1804 . $\mathrm{Na}$ atualidade, internacionalmente, é visto como uma nação que passa por um processo de recuperação, devido a décadas de crises políticas e pobreza, complementada por intervenções externas e ajuda internacional, como no caso da parceria Brasil-Haiti no ano de 2004 (Dieme, 2016). A escolha de migração para o Brasil, pode estar relacionada a forte presença do exército brasileiro no território haitiano na época das missões de paz, após o terremoto e os projetos brasileiros como o de vacinação. Bem como pouca fiscalização na fronteira brasileira; possibilidade de emprego dado ao Brasil sediar a copa de 2014; os jogos olímpicos de 2016 e a exploração do Pré-sal (Handerson, 2015; Coutinho \& Marcelino, 2016).

Nessa busca, as mulheres haitianas, entre 2010 a 2015, sozinhas ou com seus companheiros migraram para o Brasil, totalizando nesse período 22.135 mulheres que desembarcaram em nossos aeroportos. Destas, 54,1\% apresentavam visto permanente, e que trouxe à tona o despreparo da sociedade e de políticas necessárias a esse acolhimento ${ }^{4}$. Caracterizado pela busca destas mulheres, ao atendimento nos diversos serviços disponibilizados no país, incluindo os de saúde. E com isto, a preocupação quanto à compreensão que estes imigrantes têm do processo saúde-doença-cuidado e sua relação com as questões culturais (Handerson, 2015).

Em busca de um referencial teórico as autoras optaram por Foucault, pois o mesmo traz em seus trabalhos o debate acerca de corpo, hospital e cuidado de si. Ressalta-se que este não desenvolve uma teoria somente ao corpo, mas o descreve como dentro da sociedade ocidental transita, constrói suas relações e como este fenômeno está associado ao desenvolvimento tecnológico produzido pela narrativa moderna.

Para Foucault (2008) o corpo permeia um espaço geográfico, possuindo sua materialidade como algo fundamental para sua existência, sobrevivência e identificação, porém não desvinculado da sua capacidade pensante, sendo assim, ele se constrói a partir da sua historicidade. A medicina se utiliza da história que esse corpo carrega, observando muitas vezes apenas a fisiologia corporal, analisando o atlas anatômico, expressão que o próprio Foucault (2008) utiliza, para identificar aquilo que é visível com a identificação de doença ou saúde. 
O contexto que permeia as indagações que esta pesquisa busca responder está relacionado à compreensão das mulheres haitianas sobre o fenômeno doença, quais seus conhecimentos sobre saúde, seu corpo e estes ligados ao cuidado. E, para tanto, tem-se como objetivo: Identificar a percepção das mulheres haitianas quanto ao corpo, cuidado e saúde.

\section{METODOLOGIA}

Trata-se de uma pesquisa descritiva e de abordagem qualitativa, realizada no período de janeiro a julho de 2017 no Estado do Paraná. Participaram 10 mulheres haitianas que faziam parte de um programa estabelecido por uma instituição religiosa na região Sul do Brasil e que acolhe refugiados e imigrantes. Neste local é oferecido curso da língua portuguesa com foco no preparo e inserção dos imigrantes no mercado de trabalho. Foram incluídas: mulheres imigrantes haitianas entre 18 anos e 60 anos. E excluídas: mulheres imigrantes oriundas de outros países, que não conseguissem comunicar-se utilizando a língua portuguesa ou com dificuldade de entendimento das perguntas.

A abordagem qualitativa foi escolhida porque ela permite 0 aprofundamento no mundo dos significados, onde se não fosse essa abordagem, a realidade no discurso das participantes não poderia ser visível aos olhos das pesquisadoras (Minayo, Deslandes \& Gomes, 2011).

As mulheres foram convidadas à participação durante as aulas de português realizadas em uma sala da referida instituição religiosa. Após o aceite, algumas mulheres solicitaram que as entrevistas fossem realizadas neste mesmo local e outras optaram por ser em seus domicílios, o que favoreceu a observação da realidade que as cerca. Em todos os momentos foram favorecidos o anonimato e a privacidade.

O roteiro de entrevista foi composto por questões semiestruturadas, primeiro com perguntas de caráter sociodemográfico com relação à idade, tempo de residência no Brasil, escolaridade, profissão, se tinham filhos e se o nascimento destes fora no Brasil. A seguir, a mulher era direcionada a aspectos nas temáticas de corporalidade, como; "O que é corpo para você?" "E como você vê e percebe seu corpo?" "E você cuida do teu corpo como?", hospital e saúde "O que é saúde para você?" E cuidado "O que é cuidado para você?", para conseguir atingir o objetivo proposto. As entrevistas foram gravadas com a permissão das participantes, bem como optou-se por um diário de campo para anotações das observações gerais. Após, estas foram transcritas na íntegra e analisadas. 
Para a análise dos dados obtidos a partir das entrevistas, foi escolhida a técnica de Análise do Discurso, a qual indica que o debate central das entrevistas seja o tema proposto pelo entrevistador e que vai além do descrito nas falas (Ferreira \& Traversini, 2013). Após a coleta das informações sociodemográficas, o roteiro permeou apontamentos sobre corpo, saúde e cuidado e no qual o referencial foucaltiano foi utilizado por ser considerado o mais adequado como sustentação teórica, filosófica e sociológica às vozes das mulheres.

Todas as entrevistas foram realizadas, somente após assinatura do termo de consentimento livre e esclarecido, conforme Resolução 466/2012 e sob parecer do CEP 3.637.228 de uma instituição de ensino superior do sul do Brasil. O sigilo foi garantido e para tanto o uso de flores foi a opção escolhida para nomear as participantes.

\section{RESULTADOS}

As 10 mulheres haitianas que participaram da pesquisa, mantiveram-se entre a faixa etária de 24 e 45 anos e o tempo de residência no Brasil, variou de dois meses à três anos e sete meses. Quanto ao estado civil dessas mulheres, cinco declararam ser solteiras, uma em união estável, três declaram serem casadas e uma informou estar separada. Quando questionadas se tinham filhos ou não, oito mulheres declararam que sim, e destas, cinco tiveram crianças que nasceram no Brasil, três já tinham filhos ao chegarem no Brasil e duas não. Um fato que marcou as observações, foi o de que elas estavam sempre cuidando de algo relacionado ao corpo e enaltecendo sua cultura, seja fazendo tranças no cabelo ou usando vestimentas coloridas, e que são características da cultura negra.

Ao serem questionadas sobre o que significava, ou o que sabiam sobre "corpo", apontavam para si, com sorrisos e gestos de timidez e olhando para o lado ao mostrarem em seu corpo do que gostavam, como seguem os relatos:

"não sabe, eu não acho nada. (risos) cope bonita". (Rosa)

"(risos) Eu gosto bastante do meu corpo, sou bem vaidosa, passo bastante creme no corpo" (Margarida).

“Eu gosto. É toma banho, se arrumar. (risos) (gesto de timidez)" (Pluméria).

"Eu gosto. Cuidar do corpo, tem coisas que você não aplica no corpo para não prejudicar a saúde". (Crisântemo).

Nas entrevistas o enfoque que elas davam sobre o corpo, esteve voltado em como elas se vêm e o que fazem para o seu cuidar, porém, evidenciado que tal cuidado não inclui 
procedimentos relacionados a atos médicos, como no caso de uma das participantes, que referiu não pensar em realizar cirurgia plástica.

Um segundo questionamento foi sobre o que significava para elas "saúde" e, trouxeram em seu discurso, ausência de doença, a relação com o hospital, bem como a saúde ao sentir-se bem e conseguir realizar tarefas diárias como segue:

“Hospital. Hospital? É, saúde é hospital." (Rosa).

“Saúde é hospital. Porquê? Porque hospitale? Se eu tá doente, eu vá na saúde (risos) (Lírio d’água).

“[...]é quando a gente não tem doença. A saúde a gente tem que cuidar para ficar com a saúde boa, assim cuidar da alimentação, cuidar do corpo e tudo isso [...] as vezes minha mãe faz chá, as vezes ela compra remédio. Teve uma vez que fiquei 3 dias com febre ai ela me levou no hospital. " (Margarida).

"Ah, saúde é quando uma pessoa está bem, não precisa, não fica doente, sempre esta com o ânimo pôr em cima, eu acho que isso é saúde" (Orquídea).

"Quando eu ta com saúde eu trabalhar e fazer todas as coisas que precisa" (Tulipa).

“(risos). É vida” (Pluméria).

Tais relatos destacam que o ambiente hospitalar como forma de restabelecimento da saúde foi utilizado apenas quando outros métodos não obtiveram resultados efetivos. E, o manter a saúde, esteve voltado à alimentação e ao cuidar do corpo. Uma das entrevistadas trouxe em seu discurso, o uso de chás no primeiro momento a não se sentir bem, tal atitude pode ser vista como prática do saber popular cultural.

Outro questionamento foi sobre o sentido de cuidado, e os relatos trouxeram o que fazem referente à higiene, à prevenção, ao não aparecimento de doença e ao cuidado aos filhos:

"Cuidado é fazer comida, lavar roupa, cuidar da casa" (Pluméria).

"Cuidar é tiene que ta tratando sempre, como eu por exemplo eu tenho esse telefone aqui né, tieno que sempre estar cuidando para não quebrar, acho que é assim" (Orquídea)

“Cuidar é você, prevenir as coisas que podem fazer mal” (Estrelícia).

"Cuidar da comida, cuidar de tomar banho, cuidar de corpo limpo tambiem" (Tulipa)

"Se uma pessoa não cuida pode ficar doente também" (Flor de Lótus).

“Cuidar muito de bebe, por que se tem frio ele tem gripe, se não tem frio ele não tem” (Lírio d'água).

"Cuidado quando a criança ficar doente levar para hospital, cuidado é comer, dar banho, lavar roupa" (Dália). 
"Cuidado é você fazer alguma coisa que depois não vai prejudicar o seu corpo, depois. Como pode ser se a pessoa não gosta do corpo e quer fazer cirurgia plástica para ficar bem, pode ser que a cirurgia não sai bem e pode causar doença[...]" (Margarida).

Nos relatos o cuidado surge na relação do cuidar de si e do outro, no sentido de que este é voltado tanto ao cuidar da saúde, como ao cuidar do todo, para que esteja bem.

\section{DISCUSSÃO}

Antes de iniciarmos a discussão dos resultados que foram encontrados, vale ressaltar que durante o processo de coleta, verificou-se a dificuldade das mulheres no quesito linguagem. Ele representa um obstáculo de socialização e muitas vezes até de inserção no mercado de trabalho, o que as tornam vulnerável. A igreja onde são acolhidas, ao ensinar o idioma português, age em suas vidas com processo de transformação social, papel que devia ser exercido pelo Estado.

Outro dado importante a pontuar é que, sobre as mulheres que tiveram filhos em território brasileiro, pode-se criar a relação da gravidez como um facilitador para elas conseguirem permanência no país, ou até mesmo a cidadania e acesso ao sistema de saúde brasileiro, Sistema Único de Saúde (SUS). Visto que, durante a gravidez recebem acompanhamento de saúde (pré-natal) e realização de exames periódicos, o que não ocorre no Haiti com a mesma qualidade do Brasil, podendo ser este, mais um motivo para ocorrer à imigração dessas mulheres, na busca por uma melhor assistência à saúde (Santos, 2016).

Em um dos discursos foi possível identificar a prática de saberes populares, com uso de chás como forma de medicamento e que vai ao encontro do aparecimento das benzedeiras, prática comum na história dos povos afrodescendentes. Essa ação acaba sendo uma maneira de reforço dos laços com os antepassados e aumenta autoestima da população negra. Vale apontar que essa cultura também se dá em locais empobrecidos, como mecanismos de saúde (Mendes \& Cavas, 2018).

Nesta pesquisa, optou-se por organizar a discussão em três temáticas: "Tema 1: Corporalidade", "Tema 2: Hospital" e "Tema 3: Cuidado de si", perspectiva esta que emergiu do próprio discurso das mulheres. 


\subsection{Tema 1: Corporalidade}

Para melhor elucidação do termo corporalidade, fez necessário pontuar sua definição juntamente com o significado do termo corporeidade. O termo "corporeidade" é comumente referenciado ao corpo físico, orgânico e biológico, com vinculação a carne, não estabelecendo a relação deste, ao contexto de inserção. Já o termo corporalidade é definido, como conjunto das manifestações corporais, estando este em comunicação e interação ao seu meio social e natural (Soares, Kaneko \& Gleyse, 2015).

No pensamento foucaltiano, o corpo dentro da história ocidental possui uma realidade biopolitica-histórica, sendo essa corporalidade construída e reconstruída a conforme o meio, sendo essa materialidade corporal apenas o palco, no qual saberes e historicidade se projetam e o fator biológico torna-se inválido para identificação da individualidade. Assim a expressão, identificação e delimitação de corpo se faz de si para si, e é uma construção no decorrer da vida, a partir das possibilidades da existência de cada um e um processo de descoberta do seu próprio corpo (Foucault, 2002).

As mulheres participantes desta pesquisa ao falarem sobre seu corpo, utilizar gestos e maneiras de olhar para si, sinalizaram orgulho de sua cultura e origem latina africana, buscaram falar de si, de como se veem e da sua historicidade enquanto mulheres negras. Trouxeram a identificação de corpo, a partir do seu corpo e de sua identificação racial, alinhada à beleza e estética negra, visto que valorizavam as expressões de corporalidade da cultura, com uso de tranças e cabelos afros, reforçando a lógica de Foucault como explicitado anteriormente.

A estética é uma das instâncias, na qual o racismo tem grande ação e o padrão de beleza está atrelado ao padrão eurocêntrico, gerando nas mulheres negras o sofrimento com a imposição desse padrão. Ao fazerem uso de seus cabelos como são, no seu dia a dia, fazem deste, um objeto político, e se opõem ao padrão hegemônico (Freitas, 2018). O cabelo é muito mais do que vaidade ou estética, mas identidade, bem como tudo que diz respeito à beleza negra, como tranças, turbantes, peles escuras, corpos voluptuosos que valorizam essas características mostrando como essa beleza fortalece os indivíduos (Gomes, 2019). 


\subsection{Tema 2: Hospital e Saúde}

O olhar para a saúde foi modificado ao longo da história da sociedade com o nascimento da clínica. A área médica ganhou controle e passou à institucionalização dos indivíduos que eram vistos como não saudáveis. A medicina moderna na sociedade eurocentrista define o que são sinais e sintomas, e determina que essas alterações devam ser corrigidas com algum tipo de intervenção concreta, fazendo com que os hospitais sejam os locais onde o tratamento é realizado para gerar saúde (Foucault, 1998).

Vale ressaltar que a imagem hospitalocêntrica, trazida na fala das entrevistadas e corroborada diretamente por Foucault (1998) é construída na nossa sociedade. Ela determina a maneira como os corpos devem se comportar, tornando-os dóceis para se ter saúde e reforçando a ideia de que pessoas são máquinas, com uma durabilidade. Quando necessário conserto, este é oferecido somente pela estrutura da indústria médica, fazendo a relação direta da saúde com a teoria da doença (Foucault, 1998).

A Organização Mundial de Saúde define saúde como "um estado de completo bem-estar físico, mental e social e não meramente a ausência de doença ou enfermidade" (WHO, 1948). O pressuposto de uma definição que remete à busca do bem-estar pleno é considerado uma utopia, por ser esta arraigada a moldes do que é produtivo ou não para a sociedade, e, por conseguinte se existe ou não necessidade de reparação para seu funcionamento pleno.

A autopercepção das condições de saúde acontece atrelada a sua condição de trabalho em vários casos e se a pessoa fica impedida de trabalhar, isso pode refletir em sua situação de saúde. A saúde então, torna-se uma expressão do modo de viver das pessoas quando perdem alguma capacidade funcional e causa prejuízo em suas atividades diárias, incluindo o trabalho, determinando o "não estar mais saudável" (Lobo et al.,2019). As pessoas se sentem doentes quando os motivos de saúde as impedem de realizar suas atividades e projetos, conforme os relatos das mulheres haitianas.

Na perspectiva das mulheres haitianas, a saúde é vista como um todo. Suas motivações para se ter saúde foram trabalhar, ajudar seus familiares e realizar cuidados necessários a eles. Isto reflete o entendimento de que a saúde se torna reparação do que está "anormal", pois a satisfação subjetiva da saúde, se torna possível, somente após a recuperação total 
da funcionalidade das suas atividades diárias socialmente impostas pela sociedade capitalista atual (Foucault, 1998).

Algumas mulheres fizeram a comparação direta do que é saúde com hospital, o que pode ter ocorrido pela existência da autopercepção de que o que está faltando em sua saúde pode ser reestabelecimento neste local. Fato que perdura mesmo com as políticas voltadas ao atendimento da mulher, entre elas a Política Nacional de Atenção à Saúde da Mulher (PNASM), a qual descreve a importância de atendimento participativo da mulher em sua terapêutica, com valorização do seu conhecimento. Entretanto, tal percepção não se alinha à evolução no conhecimento científico entre os profissionais de saúde, que podem gerar descrédito à informação dada no contexto aqui instituído do corpo (Silva, Urasaki \& Flores, 2018).

\subsection{Tema 3: Cuidado de si}

Quanto ao cuidado de si, Foucault (2002) cita em seus estudos sobre a Antiguidade, que o cuidado deve ser uma prática realizada por todos e realizada não somente em um único momento da vida, mas em toda ela. O cuidado deve ser exercido por si, nos círculos de amizade, entre os familiares e no coletivo em que se vive. As mulheres trouxeram nos relatos o cuidado por si com práticas de vaidade no cuidado com seus cabelos e vestimentas coloridas, no cuidado com o seu corpo, com práticas ditas como saudáveis e no cuidado com seus familiares, corroborando com a prática que Foucault aponta sobre 0 cuidado de si.

A respeito da dimensão do cuidado foi possível verificar nos relatos, que as mulheres haitianas têm a preocupação com a saúde relacionada diretamente ao bem-estar familiar, estabelecendo diretamente a relação do cuidar com o universo feminino, como ação pressuposta da mulher. O gênero feminino é historicamente visto como o detentor do cuidar. Ao longo da história a mulher é provedora do cuidado, ela é responsável por garantir a manutenção da vida e sua continuidade. Em relação ao corpo, ela visa proteger e estimular o crescimento que inclui a gravidez, o nascimento, o cuidado com recém-nascidos, a criança, o cuidado com os idosos e os doentes (Fan \& Parreñas, 2018).

Atualmente com o avanço tecnológico e do conhecimento científico, as concepções do cuidado estão voltadas ao modelo biomédico, e este ao poder profissional sobre o corpo dessas mulheres (Silva, Urasaki \&, 2018). O conhecimento que cada uma tem sobre o 
cuidado e como este pode beneficiar sua saúde esteve presente nas entrevistas. Entre outros saberes, a alimentação foi destacada nas falas, porém os processos e protocolos hoje estabelecidos nos órgãos públicos, vinculam-se à Prática Baseada em Evidências (PBE), o que não contempla a subjetividade particular do sujeito (Silva, Urasaki \&, 2018).

Outro ponto com relação ao cuidado de si é o cuidar do outro em suas dimensões e permanece arraigado, independente da origem desta mulher. O cuidado do outro tem relação com questões de gênero e é historicamente construído na cultura patriarcal.

\section{CONCLUSÃO}

A pesquisa possibilitou identificar a percepção das mulheres haitianas quanto ao corpo, cuidado e saúde conforme o expresso neste artigo e a ótica foucaultiana amparou sua construção quanto ao objetivo proposto. Um fato importante e que deve ser sublimado foi a possibilidade desta pesquisa enaltecer o empoderamento negro das mulheres haitianas. Isso foi constatado com o fato que destas mulheres sentirem-se belas com a identificação dos seus corpos e uso dos valores de reconhecimento da estética da cultura de matriz africana, como tranças e vestimentas coloridas e o não desejo em alterar seus corpos com procedimentos cirúrgicos. Empoderamento necessário na luta contra preconceitos raciais que confrontam a hegemonia imposta pela nossa sociedade e a esta que segue padrões eurocentristas.

A concepção hospitalocêntrica ainda permanece impondo poder sobre os corpos, controlando sua maneira de agir e de como o corpo do indivíduo deve adotar várias práticas de comportamento para ter saúde. Esse resultado foi destaque nas falas e concepções das mulheres haitianas e é corroborado com a manutenção da visão do mundo capitalista e que enxerga o corpo como uma máquina de produção.

A pesquisa trouxe um importante recorte de gênero, no qual ainda existe a imposição do cuidado para as mulheres e um viés a ser melhor detalhado em outros estudos, frente à concepção sobre o papel da mulher determinado na sociedade, independentemente de sua origem, mas pelo fato de ser mulher. Sugere-se o aprofundamento sobre como é o acolhimento dessa população pelos trabalhadores da APS, porque mesmo que este nível de atenção à saúde escape do modelo hospitalar, vislumbra-se que siga os princípios do SUS, principalmente o da Universalidade, no qual todo indivíduo deve ser tratado como igual. 


\section{REFERÊNCIAS}

Dieme, K. (2016). Imigração haitiana e política de acolhimento institucional na cidade de São Paulo: 2010-2015. 2016. 249 f. Dissertação (Mestrado) - Curso de Filosofia, Instituto de Filosofia e Ciências Humanas, Universidade Estadual de Campinas, Campinas, SP, Brasil. Disponível em: http://periodicos.uem.br/ojs/index.php/EspacoAcademico/article/view/24740/14502.

Coutinho, S. R., Marcelino, B. A. M. (2016. Migração, religião e políticas públicas: o caso dos haitianos. Reflexão, 41(2), 225-233. Disponível em: https://seer.sis.puccampinas.edu.br/seer/index.php/reflexao/article/view/3633.

Fan Y.K., Parreñas R.S. (2018). Who Cares for the Children and the Elderly? Gender and Transnational Families. In: Ducu V., Nedelcu M., Telegdi-Csetri A. (eds) Childhood and Parenting in Transnational Settings. International Perspectives on Migration, 15. Springer, Cham.

Ferreira, M.S dos, Traversini, C.S (2013). A análise Foucaultiana do discurso como ferramenta metodológica de pesquisa. Educação \& Realidade, 38(1), 207- 226. Disponível em: http://www.ufrgs.br/edu_realidade/

Foucault, M (2008). Vigiar e punir: nascimento da prisão. Tradução de Raquel Ramalhete. 35. ed. Petrópolis: Vozes.

Foucault, M. (2002). História da Sexualidade III - o cuidado de si. Rio de Janeiro: Graal, 2002.

Foucault, M. (1998). O nascimento da clínica (5a ed., R. Machado, Trad.). Rio de Janeiro: Forense Universitária.

Freitas, G. C. S. (2018). Cabelo crespo e mulher negra: a relação entre cabelo e a construção da identidade negra. Revista Idealogando, 2(2),66-87. Disponível em: https://periodicos.ufpe.br/revistas/idealogando/article/view/238062.

Gomes, N. L. (2019). Sem perder a raiz: Corpo e cabelo como símbolos da identidade negra. Belo Horizonte Mg: Autêntica.

Handerson, J. (2015). Diáspora: Sentidos sociais e mobilidades haitianas. Horizontes Antropológicos, ano 21, 43, 51-78.

Lobo, L. A. C et al. (2019). Prevalência de hospitalizações e fatores associados em uma cidade do Sul do Brasil. Revista da Amrigs, 63(1), 49-53. Disponível em: https://www.amrigs.org.br/revista/174.

Mendes, D. S., Cavas, C. S. T. (2018). Benzedeiras e benzedeiros quilombolas - construindo identidades culturais. Interações, 19(1), 3-14. Disponível em: http://www.scielo.br/scielo.php?script=sci_arttext\&pid=S151870122018000100003\&lng=en\&nrm=iso.https://doi.org/10.20435/inter.v19i1.1568.

Minayo, M. C., Deslandes, S. F.; Gomes, R. (2011). Pesquisa social: teoria, método e criatividade. Editora Vozes Limitada.

Santos, F. V. (2016). A inclusão dos migrantes internacionais nas políticas do sistema de saúde brasileiro: o caso dos haitianos no Amazonas. Revista História, Ciências, Saúde, 23(2), 477-494. Disponível em: http://www.scielo.br/pdf/hcsm/v23n2/0104-5970-hcsm-23-2-0477.pdf. doi.org/10.1590/S0104-59702016000200008

Soares, M. G., Kaneko, G., Gleyse, J. (2015). Do porto ao palco, um estudo dos conceitos de corporeidade e corporalidade. Dialektiké, 3, 68-77. Disponível em: http://www2.ifrn.edu.br/ojs/index.php/dialektike/article/view/3725 https://doi.org/10.15628/dialektike.2015.3725

Silva, E. A., Urasaki, M. B. M., Flores, Q. R. S. (2018). Concepções de cuidado e relações de poder na saúde da mulher. Refacs, 6(1), 63-71. Disponível em: http://seer.uftm.edu.br/revistaeletronica/index.php/refacs/article/view/2795. DOI: https://doi.org/10.18554/refacs.v6i1.2795.

WHO. (1948). Officials Records of the World Health Organization, 2, 100. United Nations, World Health Organization. Geneve, Interim Comission. 